\title{
Inside the Mind of the Expert Entrepreneur: the Explorer's View of Strategy
}

\author{
Paul Cook (Corresponding author) \\ J.D. Candidate of 2012 at UCLA Law School \\ Tel: +1-310-806-3813Ｅ-mail: Cookp2012@lawnet.ucla.edu
}

Rick Yamamoto

Senior Advisor, Leading Edge Investment Advisors LLC

Tel: +1-415-217-7030Ｅ-mail: Rick@leia.net

Received: March 31, 2011 Accepted: August 15, 2011 doi:10.5430/jms.v2n3p77

\begin{abstract}
Although firms tend to rely on business plans and objective oriented approaches to their future, this paper presents an alternative model of strategy: the explorer's view of strategy. Saras Sarasvathy, a researcher at University of Virginia, found that serial or expert entrepreneurs operate under a different mode of thinking, which she calls effectuation. This paper traces how effectuation has roots in military history. Then, it explains how Sarasvathy arrived at her findings. It then presents Sarasvathy's five findings. 1) Entrepreneurs primarily form their objectives based on the resources available to them. 2) They focus on what they could lose rather than what they could expect to gain. 3) They focus on partnerships rather than competitors. 4) They continually refine their product or services by dialoguing with their stakeholders. 5) They deviate from their originally conceived business objective. Following that is an analysis of when effectuation is better employed by a firm than the classical approach to strategy. Finally, it concludes with two concrete examples. One of them shows how a big firm can utilize effectuation, and the other demonstrates how a big firm can face drastic losses by using the classical approach to strategy in an unsuitable context.
\end{abstract}

Keywords: Strategy, Strategic Thinking, Effectuation, Business Plan, Entrepreneurship

\section{Introduction}

When business leaders think of strategy, the thoughts that all too often come to mind are workshops, business plans, and objectives. This is the classical view of strategy, which assumes that a firm can control its environment and resources. It is believed that if the market analysis is correct, that the objective it wants to achieve will remain feasible within its planned timeframe, and that the environment it is in will remain constant in the future. Although there is merit in this model of strategic thinking, serial or expert entrepreneurs (i.e. those who have successfully established multiple firms) operate from a different perspective.

Expert entrepreneurs behave more like explorers, rather than rulers. (Sarasvathy 2008). Rulers function by giving orders, which they assume to be correct. They expect those orders to be carried out and believe that those orders will result in success. In contrast, imagine what explorers do. Exploring requires the journeyer to chart unmapped territories, to be resourceful, to persuade prospective patrons, and to know oneself well enough to harness her expertise and knowledge. Saras Sarasvathy, assistant professor at University of Virginia's Darden School, found that expert entrepreneurs employ an exploratory mode of thinking she termed, "effectuation." (Sarasvathy 2008).

Effectuation differs from the classical strategy, or the objective-driven one, because the means drives the objectives, rather than the expected vice-versa. An example of this would be a chef who is not given a menu in advance. A chef is escorted to a new kitchen, where she must familiarize herself with the utensils and ingredients. From what the chef has observed, the chef can draw on her previous experiences and design a menu with the resources available to her. In contrast, classical strategy calls for one to plan a menu, to buy the ingredients at the market, and then to create it. (Sarasvathy 2008).

Both modes of strategy are essential at different points in time. This paper, however, focuses on effectuation in order to explore the worldview of the expert entrepreneur. It then advocates its utility in turbulent and unforeseeable market environments. It will introduce effectuation by showing how past military leaders used this approach. Then it will 
present Sarasvathy's insights into expert entrepreneurs, examine when effectuation should be harnessed, and conclude with two practical examples. One of these examples will show how a big firm can utilize effectuation and reap revenue, while the other will demonstrates how a big firm can face drastic losses by using the classical approach to strategy in an unsuitable context.

\section{Military View of Two Different Models of Strategy}

When leaders think of strategy, they define it as a plan that can meet an objective. Yet, this view of strategy does not account for moments of genius in the fields of the military and business. On April 8, I781, George Washington wrote a letter to the President of Congress, in which he admitted, "[W]e are surrounded for want of money, [which] will convince Congress of the impracticability of my fixing at this time on any definitive plan of campaign . . .” (Adams, 1931). In short, there was a point in time when Washington was without a definitive military plan and under-resourced. Yet, he was ultimately able to force a surrender from the world's most powerful, undefeated military at the time. To turn to a business example, the founders of internet search engine Google, Page, Schmidt, and Brin, had not initially planned for their services to expand beyond internet engine searches, but they have now developed innovative services such as Google Maps, which allows for users to see a street view of the entire United States through their internet browser. (Note 1). (Brin \& Page 1998). Strategy, as it turns out, can start with the objective and sometimes strategy can actually precede the objective.

This complexity has been observed historically in the battlefield. (Yamamoto, 2009). (Note 2) The two fathers of modern strategic studies, Baron Antoine Jomini and Carl von Clausewitz, observed the same general and the same battles, but drew two different conclusions about why the general succeeded. (Duggan 2007). The general the two observed was Napoleon Bonaparte. He is and was known as the god of war because he was the most successful battlefield general in human history. (Englund 2004).

Jomini attributed Napoleon's success to precision and strategic planning. In his war treatise, entitled Summary of the Art of War, Jomini gave a formulaic approach to win a battle. First, the general must choose a base to operate from. (Duggan 2007). Second, he must choose an "objective point.” Third, he must choose a line of operation to get from his base to the objective point. (Duggan 2007).

This line of reasoning is analogous to strategic planning. The CEO must decide where the firm stands. Then she must decide the firm's long term goal. Finally, the CEO must allocate temporal, human, technological, and financial resources to get from point $\mathrm{A}$ to $\mathrm{B}$.

In contrast, Clausewitz emphasized Napoleon's intuition over planning (Duggan 2007). Clausewitz entered academia in 1810 to explicate the reasons behind Napoleon's battlefield genius. His contribution to strategy was captured in the treatise, titled On War. Although his treatise is written in dense German, Clausewitz relied on the French language to convey one and only one concept: coup d'oeil. The modern English translation, which does very little justice to the concept, is "the glance.” (Duggan 2007). A literal translation would be to strike the eye. (Duggan 2007). An even more modern equivalent of this concept is in Malcolm Gladwell's concept of "Blink.” (Gladwell 2007). Napoleon would experience coup d'oeil when he was assessing the battlefield terrain, his garrison's morale, his own force, and his opponent's force. (Duggan 2007). In a series of insights, Napoleon would abandon old assumptions and redirect his forces against hidden strategic points. (Duggan 2007).

Clausewitz believed these insights were the primary driving force behind Napoleon's victories. (Duggan 2007). His treatise emphasized Napoleon's prowess in drawing from previous battlefield and academic experiences in order to re-apply those lessons to unfamiliar combat environments. Napoleon worked with a fluid plan in mind, one he was willing to relinquish or modify according to any revelations from his coup d'oeil. (Duggan 2007).

He had two advantages in doing so. One, the general would not lock himself into a failing plan by adhering to it as the cost of his army. Two, by carefully assessing the terrain, the garrison's forces, and his own resources, Napoleon was crafting a strategy that would maximize the utility of his force.

And even though Clausewitz had the more nuanced understanding of the general, it would be Jomini's view of war, which would prevail for over a century and a half. (Duggan 2003). According to William Duggan, this was primarily because Jomini was easier to understand in both concept and language. Jomini wrote in simple French, and in comparison, Clausewitz wrote in complicated German. Further, Jomini's concepts were both simpler and easier to execute. (Duggan 2007). It was not until the early 1970's that there was a revival of Clausewitz and his work in the United States. (Melton, 2009). Comparatively, Jomini's work was commonly taught to American military cadets, including William Sherman and Robert E. Lee at West Point Military Academy. (Smith 1997). Clausewitz's work was still not available to cadets in the Civil War because there was no adequate translation of his work. (Smith 1997) 
Perhaps, audiences have changed little from then to now. Most business books and journals are focused heavily on strategic planning and formulaic solutions to complex and multi-factored problems. There is less emphasis on intuition, expertise, and leadership.

Take for instance, Harvard Business Review’s (HBR) June, 2011 article on strategy: The Big Idea: Before You Make that Big Decision. In the article, the authors advocate for the new startup to be weary of confirmation bias. Yet, the HBR article does not disclose that the big idea may be risky and that such a goal-oriented strategy could lead to a waste of resources. This mode of thinking, the objective-driven strategy, comprises one valid leg of strategy. The other and more neglected one is a resource-focused view of it. For an organization to be mobile, it needs both legs to carry it. The remainder of this paper focuses on effectuation, an underutilized and atrophied leg of strategy.

\section{The Explorer's View of Strategy}

\subsection{Inside the mind of the explorer}

If military strategy has two branches of thought, does the same apply in business? Businesses define strategy, much the same way as Jomini outlined it. Only now, it is captured in business plans, objectives, and timeframes. Thus the question is presented: Is there a strategic way of thinking that reflects Clausewitzs' explanation of strategy? Sarasvathy set out to answer this question. She was fascinated by expert or serial entrepreneurs. She sought the answer to this question: Did experts entrepreneurs differ in their thinking from novices (2008)? Sarasvathy defined an expert

as a person who, either individually or as part of a team, had founded one or more companies, remained a full-time founder/entrepreneur for 10 years or more, and participated in taking at least one company public. [Her] last criterion not only satisfied a very stringent definition of entrepreneurial expertise, but also provided additional data about the actual experience of the subjects in the form of annual reports, press kits, etc. (2008).

After narrowing her criteria, she selected entrepreneurs from two sources. Her first source was a list of the 100 most successful entrepreneurs from 1960-1985 compiled by, David Silver, a venture capitalist. Her second source was the national winners of the Entrepreneurs of the Year awards, complied by Ernst \& Young. From those two sources, Sarasvathy selected 245 participants, of which 45 agreed to be interviewed. The 45 were subjects from 17 states. $90 \%$ were American. They ranged in age from 41 to 81 years old, and their companies were worth anywhere from $\$ 200$ million to $\$ 6.5$ billion. (Sarasvathy 2008).

To map their thinking, she employed the "think-aloud” verbal protocol. The think-aloud protocol requires participants to verbalize what they are thinking at the moment they are doing a specified task or solving a specified problem. (Lewis 1982). Participants are asked to verbalize what they are looking at, thinking, doing, and feeling as they go about their assignment. The soundness of this model has been revalidated in 2000. (Sarasvathy 2008). Kuusela and Paul noted that,

[i]n general, the concurrent protocol analysis method outperformed the retrospective method.

Not only was the number of concurrent protocol segments elicited higher than that of retrospective protocol segments, but concurrent data provided more insights into the decision-making steps occurring between stimulus introduction and the final choice outcome."

By harnessing this methodology, Sarasvathy asked her participants to solve ten decision problems that are often faced in a startup. The study took two hours: ninety minutes of the time was focused on the problem, while the thirty minute remainder was used for an additional interview. To have a control for her experiment, the researcher gave the novices, represented by MBA students, the same problem set as the entrepreneurs. (Sarasvathy 2008).

\subsection{The results: the difference between rulers (novices) and explorers (experts)}

The study revealed that there was a marked difference between the novices represented by MBA students and experts represented by the serial entrepreneurs. (Sarasvathy 2008). Sarasvathy identified five elements (Note 3), which differed between a novice and expert entrepreneur. What emerged in her study is that the two groups employed different logical modes of thinking. The expert entrepreneur primarily harnessed "effectuation”; whereas, the novice thought with Causal logic. Causal thinkers behave like "rulers," who are confident that their resources can complete their desired objective. In contrast, effectuators have a mindset more analogous to explorers (Sarasvathy 2008), who are discovering uncharted lands (a good example would be Edmund Hillary and Tenzing Norgay who decided to conquer Mount Everest without knowing what waited atop).

Sarasvathy succinctly describes the difference in the two logical modes:

Causal problems are problems of decision; effectual problems are problems of design. Causal 
logics help us choose; effectual logics help us construct. Causal strategies are useful when the future is predictable, goals are clear and the environment is independent of our actions; effectual strategies are useful when the future is unpredictable, goals are unclear and the environment is driven by human action. The causal actor begins with an effect he wants to create and asks, "What should I do to achieve this particular effect?" The effecutator begins with her means and asks, "What can I do with these means?" And then again, "What else can I do with them?" (Sarasvathy 2008).

Her study revealed that the two modes were distinguishable by five factors.

\subsubsection{Resource driven objectives}

The first and most definitive element that separated experts from novices was how they started their decision making process when forming a business. (Sarasvathy 2008). The novice started with a business plan (with its corresponding objectives) and market research. Expert entrepreneurs, on the other hand, asked three primary questions: 1) Who am I? 2) What do I know? 3) Who do I know? In doing so, the entrepreneur was rigorously inventorying his resources. What services or goods does the entrepreneur already know how to provide? By asking who he is, the entrepreneur identified those things about what he was most passionate about. Finally, the most extreme of effectuators always began with who they knew; so, they could start building partnerships. For instance, one participant said,

Traditional market research says, you do very broad based information gathering, possibly using mailing. I wouldn't do that. I would literally, target, as I said initially, key companies who I would call flagship, do a frontal lobotomy on them ... The challenge then is really to pick your partners, and package yourself early on before you have to put a lot of capital out. (Sarasvathy 2008).

This line of thinking is much similar to that of Napoleon's coup d'oeil. Like in the Battle of Toulon (Note 4) Napoleon had not decided which strategic point to conquer, until he rigorously surveyed the resources and his location. (Duggan 2009). Similarly, expert entrepreneurs survey their resources before making a significant decision.

\subsubsection{Minimizing losses rather than focusing on returns}

The second element was that entrepreneurs wanted to spend only what they could afford to lose. (Sarasvathy 2008). In contrast, novices focused on how much they would expect in returns. The extreme effectuators wanted to spend no money at all. All of them were cautious in spending money in marketing the product. One entrepreneur would even market a product that was still not available to a client. He would build it, only after the client wanted to buy it. (Sarasvathy 2008).

\subsubsection{Forming partnerships}

The third element was that expert entrepreneurs differed from novices in that they stressed finding partners. First, they attempted to quickly convert customers into partners - who would join them in their fledgling business. Second, unlike the novices - who focused on competition, experts were diligent about building their partnerships.

3.2.4 Refining the service or product based on customer feedback

The fourth element was that expert entrepreneurs acknowledge that their original product is not where it should be. (Sarasvathy 2008). By soliciting reiterative feedback from the client on the product or service, the entrepreneur is able to transform it. In doing so, the expert entrepreneur does not come up with a preconceived idea to tell the market what it needs. Rather, the entrepreneur and the market enter into a dialogue to determine what the market wants. (Sarasvathy 2008).

\subsubsection{Arriving at a different destination}

The fifth and final element was that expert entrepreneurs do not have a fixed objective or destination. For instance, unlike the classical strategic model, the journey from A to B often became a journey from A to C, C being an unimagined or deviant destination. Two-thirds of the participants in the study, ended up selling products or services that were different from their original one. (Sarasvathy 2008). This is again resonant with Napoleon's coup d'oeil. Napoleon's final battle plan and strategic points changed from his pre-battle plans. Likewise, when entrepreneurs use a means-based orientation, they must alter their original plans to the dynamics of their resources, knowledge, partnerships, clients, and environmental change. (Sarasvathy 2008). 


\section{The Limitations of Operating in the Classical Strategic Model}

This section of the paper shows the two limitations of classical strategy. First, classical strategy is optimal in contexts, where the future can sufficiently be understood and controlled. Second, classical strategy is not well designed to handle unexpected changes in the environment. In contrast, this paper demonstrates that the explorer's strategy can work around the constraints of classical strategy.

4.1 The first limitation: classical strategy is optimal only when the environment and the future can be sufficiently understood

An underlying assumption of the classical model of strategy is that the future could be sufficiently understood. For classical strategy to work, three factors must be certain. The first is that the crucial factors of any given environment could be understood adequately enough by an organization or a person to plan a successful strategy. The second is that the environment will be static enough for the predetermined objective to remain valid and achievable within the planned timeframe. The third premise is that the model functions within the framework of a closed or isolated system. What all this assumes is that change will not be introduced to the operational environment.

Consider for example, the long term business plans that organizations draft. How often does the long term objective remain the same for a ten year plan? From the authors' experience, organizations can barely hold onto a three year goal, especially during these turbulent economic markets.

The flaws of the classical model are mainly embedded in the first and third premises. This is because these premises do not hold firm under all circumstances. For instance, in a chaotic or complex socioeconomic environment, such as the one we are experiencing now, the environment cannot be adequately understood. Boone and Snowden go so far as to suggest that in a chaotic environment, there is no point in looking for the right answers since there is no clear cause-and-effect relationship. Similarly, chaos theory (also known as the butterfly effect), stipulates that dynamic systems can evolve over time, such that they become highly sensitive dynamics that have drastic effects on the whole system (Hillborn, 2004). In such chaotic systems, the classical model cannot be harnessed by the strategist.

Returning to the menu metaphor used earlier for an example, producers of the American-reality-competition-culinary-challenge-show, Top Chef, understood that sudden changes into a competitor's environment can weed out the weak. Conversely, such environments also draw out extraordinary talent from the "top chef(s)." (Top Chef Miami, 2007). For instance, in the first episode of Season 3, the chefs are asked to create a "surf and turf" dish using exotic proteins. (A surf and turf is a main course prepared by pairing seafood and meat, such as the classic lobster and steak). In this episode, the surf and turf options consisted of exotic ingredients like geoduck, monkfish liver, sea cucumber, snake, alligator, abalone, sea urchin, jumbo squid, goat leg, duck tongue, black chicken, and kangaroo (Note 5).

The challenge tested the competitors' ability and tolerance to work with exotic and strange resources. In order to win, a competitor needed to transfer and apply his previous knowledge of food to what was in front of him. He also had to do so confidently and under temporal and competitive pressures (Note 6). The competition parallels what the CEO faces when the market environment changes or when the firm is undergoing a restructure. In such situations, one is better positioned to maximize resources, rather than adhere to preconceived objectives, which may no longer function in a shifting or unknown environment.

The second assumption identifies a deep flaw in the classical model. Advances in knowledge and technology make it almost impossible to hold a specific objective for any set period of time. This is because scientific knowledge is constantly compounding against itself. For instance, one estimate suggests that scientific knowledge doubles every 18 months (Terheyden 2007). This means that if a firm sets a goal with a timeframe of longer than five years, the firm may be aiming to achieve an objective that will soon become outdated, or the objective remains based on outdated information.

\subsection{The explorer's model of strategy can work successfully in unpredictable environments}

If entrepreneurs subscribed solely to the classical model of strategy, then they too would be unable to start successful enterprises within a chaotic environment. Expert entrepreneurs, however, employ the explorer's strategy. (Spinosa, 1999). This is because entrepreneurs form the objective by engaging the stakeholders in discussions. Thus, the objective is continually being formed, assessed, and re-formed. In doing so, the objective never takes priority over the stakeholder. Furthermore, the objective is not strictly set and can be modified to fit a turbulent environment.

Entrepreneurs can also avoid environmental restrictions imposed on them by transcending the context. In a puzzling way, the entrepreneurs interviewed did not view environment as a constraint. Rather, they make the environment 
submissive to them. Sarasvathy and her co-writers (2007) assert:

[W] hile some entrepreneurs might act as though they have little control over their environments and seek to create new ventures within given environments, there is little doubt that others can and do act as though environments are artifacts - i.e. they seek to make new environments, be they new markets, industries, technological regimes, institutions and norms and/or even socio-economic and cultural ecologies. The key point, in fact, is not that entrepreneurial action changes the environment.

\section{Instead the point of real import is that the universe of available actions when one acts as though the environment is given - versus when one acts as though the environment is an artifact constructible through one's actions - is very different.}

We cannot be completely certain as to the mechanics of how the entrepreneur does so. We do observe, however, that certain ones have the extraordinary ability to work outside of their system to create a new one . (Spinosa 1999).

4.3 The second limitation: classical strategy encourages strategy as a purely intellectual exercise to the detriment of the strategist and her firm

Perhaps the most obvious attributes missing from the classical strategy model but present in effectuation are the elements of leadership and social intelligence. Classical strategy treats the journey to success as a scientific process. The common misconception is that if you have a destination and resources, you have the ingredients to produce a successful firm. In actuality, the results of failed firms show that this does not always hold true. Resources and logical plans are not enough. Howard Gardner, a cognitive scientist, provides some potential explanations. His studies have shown the importance of interpersonal intelligence, which comprises a specialized category of intelligence. (Gardner 1987). He defines it as extroversion combined with a person's ability to be sensitive to others' moods, feelings, temperaments and motivations, and their ability to cooperate in order to work as part of a group. Interpersonal intelligence is used to communicate effectively and empathetically with others (Gardner 1987). The classical model of strategy, however, underemphasizes the role of interpersonal intelligence and social intelligence because it does not require it.

\subsection{Expert entrepreneurs embed leadership in their effectuation logic}

Entrepreneurs, unlike those who adhere to classical strategy, are continually employing interpersonal intelligence when selling their venture to the "right" stakeholders; in doing so, they give ownership of the venture to the stakeholders. They are simultaneously exercising their leadership skills by having stakeholders self-select themselves because "the skill of the entrepreneur lies in his or her ability to stitch together a valuable venture from a variety of real commitments from a number of self-selected stakeholders, each of whom may have a different conception.” (Sarasvathy 2007). Prominent among the abilities of an expert entrepreneur is the art of persuasion and communication.

Essentially, when one views leadership as influence, entrepreneurs are leaders. Without their ability to convince stakeholders to journey with them, their ventures would fail. An inherent flaw in the classical model of strategy is the absence of an emphasis on leadership. In contrast, leadership is the foundation of the effectuation model of strategy.

\section{Conclusion}

The common assumption about strategy is that one should start with the objective first and only then, should the resources be assessed and utilized in a manner to achieve that objective. This is the classical approach to strategy. In this article, we presented an alternative model of strategy. Sarasvathy, the researcher who was able to map this alternative model named it effectuation. She mapped this model by analyzing the verbal responses of select expert entrepreneurs while they solved a set of ten problems. From their responses, Sarasvathy identified five common factors. 1) Entrepreneurs primarily form their objectives based on the resources available to them. 2) They focus on what they could lose rather than what they could expect to gain. 3) They focus on partnerships rather than competitors. 4) They continually refine their product or services by dialoguing with their stakeholders. 5) They deviate from their originally conceived business objective. These factors distinguished their decision making from novices, which were represented by MBA students.

The most interesting of these findings is that the strategic objective could be formed by assessing the resources available to the entrepreneur. Even large firms can take advantage of this principle. We return back to Google, an organization used as an example earlier in this article, because it appears that Google has tapped into effectuation logic, especially the 
resource-driven aspect of it. Google does not entirely dictate what its employees should do. (New York Times, 2007). It largely trusts its employees to define their own goals and objectives. For example, Google encourages its engineers to take 20 percent of their time to work on something that interests them personally and is related to the company. For instance, if an engineer has an idea he would like to explore, the time and resources are available to research it and render it as a product or service. Products such as Gmail, Google News, and Google Shuttles have resulted from this 20 percent time. (New York Times, 2007).

In contrast, firms can face ruin by strictly adhering to the classical approach to strategy. The American Walmart faced defeat by utilizing classical strategy when it launched its operations in Germany. (Knorr, 2003). When Walmart entered the German market, it focused on how much revenue was to be made. It believed that it could at least make $€ 1.87$ billion. (Note 7). Instead, Walmart faced terrible losses, which eventually totaled nearly $€ 1.0$ billion.

The prospects for big gains blinded Walmart to obvious differences in the two cultures. It assumed that the German marketplace would be the same as the American one. Thus, its strategy was simple: replicate what it did in America. Unfortunately for it, Walmart "pursued a fundamentally flawed internalization strategy due to an incredible degree of ignorance of the specific features of the incredibly competitive German retail market.” (Knorr, 2003, Italics added for emphasis). These mistakes may have been mitigated if it asked different questions before it bought its infrastructure. But because Walmart operated under the classical approach to strategy, it neglected to determine what it did not know about the new marketplace. This is because the ruler's approach to strategy, as mentioned in the introduction, leaves no room for the questioning of assumptions. In other words, rulers almost always believe they are right.

For instance, in Walmart's case, it ignored one pivotal fact. German consumers purchase goods in an independent and private manner. Walmart's American model of customer service is premised on greeters and providing assistance to shoppers. Therefore, the extra assistance, which would be welcomed by Americans, was not appreciated by German consumers. Furthermore, a secondary effect resulted with extra overhead costs. This in turn, led to Walmart sustaining an uncompetitive position in the incredibly competitive German retailer market. The cumulative consequence for Walmart was that it could not undercut its German competitors, and thus, it could not replicate its tour de force gorilla-tactics in Germany.

Two effectuation questions, which could have mitigated Walmart's flawed decision making, are 1) how much could Walmart bear to lose when starting this experimental venture, and 2) who are potential domestic partners? The first question would have forced Walmart to focus its decision making based on reducing risk. Thus, Walmart would be forced to have identified more risks and subsequently, more risk mitigating strategies. The second question inherently reduces risk by spreading it out amongst more stakeholders. Also, domestic stakeholders would have challenged the flawed assumptions that Walmart was making. We assume Walmart would have listened.

These are the same questions that a firm may want to ask when starting a new venture or when operating in an unfamiliar or unstable market environment. In order for a firm to be optimal, it must not neglect the explorer's view of strategy. The two modes of strategy do not need to be in operation simultaneously. Yet, it is in the firm's advantage to know when to apply one strategy over the other. Not only could a firm thrive by adopting the explorer's view of strategy, studies have also shown that entrepreneurs can actually change the environments they are in. (Spinosa, 1999). Further research will need to explore the mechanics of how entrepreneurs actually transform their environment around them.

\section{Acknowledgement}

A special thanks to The School of Government, Victoria University of Wellington, New Zealand, for encouraging and sponsoring this research. Also, thank you to David McLachlan, Brett Priddey, Radley Neethling and Kym Fowlie for fostering my curiosity, growth, and learning, while I served under them. Thank you to Carolyn Silllman, David Beadles, Lance Beath, Connie Chang, and Anna Baycher for their help in revising this piece.

\section{References}

Adams, R., (1931). A view of Cornwallis's surrender at Yorktown, The American Historical Review, 37(1), pp. 25-49. http://dx.doi.org/10.2307/1842255

Brin, S., and Page, L., (1998). The Anatomy of a large-scale hypertextual web search engine. Computer Networks and Isdn Systems 30: 2. http://dx.doi.org/10.1016/S0169-7552(98)00110-X

Duggan, W., (2003). The Art of what works: how success really happens. New York: McGraw Hill, (Chapter 2). 
Duggan, W., (2007). The Corsican conquers Europe: Coup d'Oeil in classical military strategy, In W. Duggan (Eds.) Strategic intuition: the creative spark in human achievement (pp. 55-67). New York: Colombia University Press.

Englund, S. (2004). Napoleon: A Political Life. New York: Scribner, (Chaper LXX).

First Impressions, Top Chef Miami, By Magic Elves Production, Bravo. (June 13, 2007).

Gladwell, M. (2005). Blink, New YorkLittle, Brown, and Company, (Chapter 1).

Hilborn, R. (2004). Sea gulls, butterflies, and grasshoppers: A brief history of the butterfly effect in nonlinear dynamics. American Journal of Physics 72: 425-427.

Kahneman, D, Lovallo D, and Sibonv, O, (2011). The big idea: Before you make that big decision . . . , Harvard Business Review (June).

Knorr, A., Amdt, A., (June, 2003) Why Did Wal-Mart Fail in Germany (So Far)?, in: Materialien des Wissenschaftsschwerpunkts "Globalisierung der Weltwirtschaft" (Weiße Reihe) der Universität Bremen, Band 24, Bremen, http://www.wiwi.uni-bremen. de/iwim/ publikationen/pdf/Weisse-Reihe/w024.pdf).

Kuusela, H. and Paul, P. (2000). A comparison of concurrent and retrospective verbal protocol analysis. American Journal of Psychology, 113: 387-404.

Lewis, C. H. (1982). Using the "Thinking Aloud" method in cognitive interface design. Technical Report IBM RC-9265.

New York Times, (Oct. 21, 2007). The Google way: give engineers room. Available at http://www.nytimes.com/2007/10/21/jobs/21pre.html.

Sarasvathy, S., (2008). Effectuation: elements of entrepreneurial expertise. Northampton: Edward Eglar Publishing, (Chapter 2-3).

Sarasvathy, S., Dew, N., Read, S., \& Wiltbank, R. (2007). Empirical investigations of effectual logic: implications for strategic entrepreneurship. paper presented at the entrepreneurship theory and practice conference on strategic entrepreneurship.

Snowden, D.J. Boone, M. (2007). A leader’s framework for decision making. Harvard Business Review, pp. 69-76.

Spinosa, C., Flores, F., \& Dreyfus, F., Fernando F., and Dreyfus, H., (1999). Disclosing new worlds: entrepreneurship, democratic action, and the cultivation of solidarity. In Spinosa, C. et. al. (Eds.) Entrepreneurship: the skill of cultural innovation, (pp. 34-69) Boston: MIT Press.

"strategy, n." Oxford English Dictionary Additions Series. (1987). OED Online. Oxford University Press. 13 Mar. 2007 $<$ http://dictionary.oed.com/cgi/entry/50238986?query_type=word\&queryword=strategy\&first=1\&max_to_show=1 0\&sort_type=alpha\&result_place=1\&search_id=NFI2-FcMilp-13778\&hilite=50238986>.

Terheyden, van Nick Nippert, Matt. (2007). Interview on speech recognition cognition. http://speechrecognition.wordpress.com/2007/11/26/clinical-knowledge-doubles-every-18-months/

Yamamoto, Rick (January 8, 2009) Speech on Entrepreneurial Expertise, The Origins Project, Eimeldingen, Germany

\section{Notes}

Note 1. Page and Brin’s original goal was to create a single, integrated and universal digital library.

Note 2. The classical definition of the word strategy, comes from the Greek word strategus meaning "office of generalship” (OED).

Note 3. This paper combined two of her six elements into one, as they were rather similar. It collapsed her third and fourth elements, which respectively states that entrepreneurs turn customers into partners, and entrepreneurs focus on partnership rather than competition. (Sarasvathy 2009).

Note 4. In Toulon, Napoleon had an option of choosing between the main fortress that the British occupied or smaller ones. Counter to his general's logic, he chose the smaller ones because his lessons from Joan de Arc and George Washington taught him that the garrison could be driven out by conquering the surrounding smaller fortresses. (Duggan 2009).

Note 5. Incidentally, the winner made ostrich fillet with tomato risotto with an abalone reduction. 
Note 6. Competitors lost for being too timid with their exotic ingredients, both in the preparation and presentation of them.

Note 7. This can be inferred by adding the revenue from the two stores that Walmart acquired. Wertkauf and Spar Handels were making $€ 1.02$ billion and $€ 850$ million respectively.

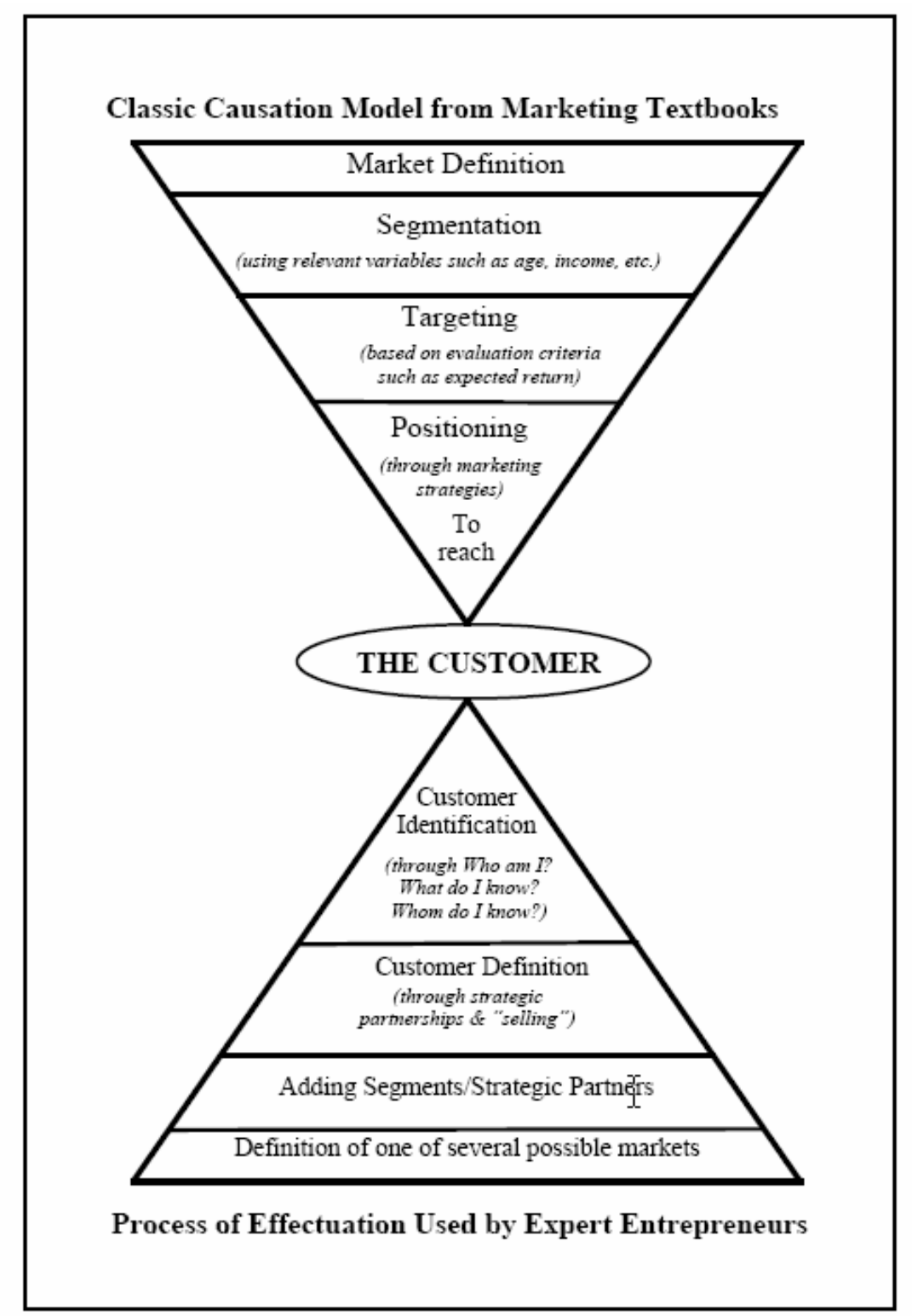

Figure 1. Sarasvathy (2009) p. 39. 